\title{
Spinocerebellar ataxia type 20
}

INSERM

\section{Source}

INSERM. (1999). Orphanet: an online rare disease and orphan drug data base.

Spinocerebellar ataxia type 20. ORPHA:101110

Spinocerebellar ataxia type 20 (SCA20) is a very rare subtype of type I autosomal dominant cerebellar ataxia (ADCA type I; see this term). It is characterized by cerebellar dysarthria as the initial typical manifestation. 